\title{
Disparities in health outcomes among seniors without a family physician in the North West Local Health Integration Network: a retrospective cohort study
}

\author{
Alexandrea Peel MD, Iris Gutmanis PhD, Trevor Bon MD
}

Abstract

Background: The relationship between having a family physician and in-hospital and postdischarge health outcomes among older adults is unclear. We ascertained the proportion of seniors who did not have a family physician and were admitted to an Ontario tertiary care centre, and we determined the association between having/not having a family physician and in-hospital mortality, 1-year mortality and readmission after live discharge.

Methods: This was a retrospective cohort study of community-dwelling seniors who were admitted to a medical service at Thunder Bay Regional Health Sciences Centre. We conducted regression analyses adjusted for demographic factors, prior health care utilization, and factors associated with the index admission to determine the association between family physician status and the study outcomes.

Results: Among the 12033 seniors admitted to hospital between Apr. 1, 2004, and Mar. 31, 2013, 40.7\% lacked a family physician. Among those without a family physician, 8.0\% (390/4899) died during the index admission and 15.8\% (714/4509) died in the subsequent year. Adjusted regression models showed that not having a family physician was significantly associated with in-hospital mortality (odds ratio 1.56, 95\% confidence interval [Cl] 1.33-1.83). Regression models of all-cause 1-year mortality and readmission also suggested that lack of a family physician was associated with detrimental health outcomes (hazard ratio 1.14, 95\% $\mathrm{Cl} 1.04-1.26$; subdistribution hazard ratio $1.17,95 \% \mathrm{Cl} 1.10-1.24$, respectively).

Interpretation: Elders without family physicians were disadvantaged during their hospital admission as well as in the subsequent year. Additional interventions aimed at increasing the proportion of seniors admitted to hospital who are connected with a family physician are warranted.

W hile access to family physicians is of concern to many Ontarians, ${ }^{1,2}$ this issue is particularly salient to residents of the North West Local Health Integration Network. The multiple health benefits of having a family physician are well documented. For example, people who have a family physician have lower rates of emergency department use ${ }^{3}$ and are more likely to report that they received routine monitoring of health issues or check-ups. ${ }^{2}$ Yet, an estimated $16.2 \%$ of residents in this health region do not have a family physician; by comparison, $6.2 \%$ of residents across the entire province lack a family physician. ${ }^{4}$ Further, only $23.8 \%$ of residents in the North West Local Health Integration Network indicated that they accessed primary care within 48 hours of illness, whereas $43.6 \%$ of Ontarians said they $\mathrm{did}^{4}{ }^{4}$ The vast geography of the area served by this network also poses access challenges. Although $46.0 \%$ of the North West Local Health Integration Network's residents live in Thunder Bay, $34.2 \%$ live in rural areas and $19.8 \%$ live in small- and medium-sized population centres scattered across $47 \%$ of Ontario's land mass. ${ }^{4}$ Consequently, some people need to travel hundreds of kilometres by land, water and air to access health care services. ${ }^{4}$ Even more troubling is the fact that between February 2009 and March 2017, of the 1325 people with high health care needs who did not have a family physician and were registered with Health Care Connect (an Ontario Ministry of Health and Long-Term Care program designed to help Ontarians without a primary health care provider find one ${ }^{5}$ ),

\section{Competing interests: None declared.}

This article has been peer reviewed.

Correspondence to: Alexandrea Peel, alexandrea.peel@gmail.com CMAJ Open 2019. DOI:10.9778/cmajo.20180004 
only $782(59.0 \%)$ were able to find a family physician whereas $87.7 \%$ of Ontarians in the remainder of the province were able to do so. ${ }^{6}$

Access to a family physician is important for everyone, but particularly for seniors, who are more likely to have multiple chronic health conditions. ${ }^{7}$ Furthermore, elders without family physicians may be disadvantaged both during a hospital admission and after discharge. Older adults without a family physician may not have received optimal health care before being admitted to hospital. As well, while in hospital, they may be put on medications requiring ongoing titration and may undergo tests that require follow-up by a communitybased primary care provider. Hospital-based health care providers at the Thunder Bay Regional Health Sciences Centre, the sole tertiary care hospital in the North West Local Health Integration Network, have noted these and other challenges when admitting, caring for and discharging seniors without a family physician. This study sought to ascertain the proportion of seniors admitted to tertiary care for medical reasons who did not have a family physician and to assess their differential risk of in-hospital mortality after accounting for demographic and health-related factors. To see if any disadvantage persisted, the association between having/not having a family physician and mortality and readmission 1 year after live discharge was examined.

\section{Methods}

\section{Study cohort}

Data analysts from ICES created a retrospective cohort of adults aged 65 years and older who at the time of their index admission were living in a private residence and had been admitted to a medical service at Thunder Bay Regional Health Sciences Centre. Given that most residents of longterm care homes receive care from an onsite physician, eligibility was restricted to seniors whose primary residence was not institutional. Those admitted for surgical and psychiatric reasons were also excluded because the reasons underpinning their mortality and readmission differ from those of medical patients. ${ }^{8,9}$

First, all patients discharged from Thunder Bay Regional Health Sciences Centre between Apr. 1, 2004, and Mar. 31, 2013, were identified using the Canadian Institute for Health Information's Discharge Abstract Database. The confidential ICES number assigned to each Ontario resident eligible for health care ${ }^{10}$ and then applied to all held databases ${ }^{11}$ was used to link patient information across data sets. People could only appear once in the study database and the first date of hospital discharge during the study time frame was the index case discharge date. Next, those who had resided in a long-term care home in the 30 days before the index admission were excluded from the study data file. Identification of this subset was based on information from the Discharge Abstract Database (not admitted from long-term care), the Ontario Health Insurance Plan claims database (no codes indicating "nursing home" or "health facility" residency), the Ontario Drug Benefit claims database (the absence of a long-term care home flag) and the
Continuing Care Reporting System: Long-Term Care database (no discharge from long-term care).

\section{Exposure variable}

Patients who had been rostered with a family physician on the index admission date according to the comprehensive Client Agency Program Enrolment database were considered as having a family physician. This includes patients who received health care from solo practitioners as well as those rostered with family physicians working within a number of primary health care models, including primary care networks, family health networks, family health groups, family health organizations, health service organizations, group health associations, patient care groups, family health teams and the Group Health Centre, and through the Rural and Northern Group Physician Agreement.

\section{Study covariates}

Factors thought to potentially influence the association between physician status and the study outcomes were included in the analyses. Baseline demographic characteristics (age, sex, local health integration network of patient residence, postal code) were obtained from the Registered Persons Database. The Postal Code Conversion File ${ }^{12}$ was used to determine income and rural/urban status. Income was divided into quintiles (for details see Appendix 1, available at www.cmajopen.ca/content/7/1/E94/suppl/DC1]). Dates of admission and discharge, admitting service, locations from which patients were admitted and to which they were discharged, and number of days in the intensive care unit were obtained from the Discharge Abstract Database. Three admission categories were created. Two of the categories were based on the Discharge Abstract Database admission categories (urgent: with a life-threatening condition or unexpected health problems requiring immediate assessment and treatment; elective: scheduled to come to the hospital in advance)..$^{13}$ The third category was assigned to those who had been transferred to Thunder Bay Regional Health Sciences Centre from another acute care hospital. Length of stay was based on the full episode of care for the index admission (from the date of admission to Thunder Bay Regional Health Sciences Centre to the date of discharge either directly from tertiary care or, for those who were immediately transferred to a different acute care hospital following tertiary care discharge, from their local hospital [for details see Appendix 1]). Health care utilization was based on information in the Ontario Health Insurance Plan database (all physician visits in the year before the index admission) and the National Ambulatory Care Reporting System database (all emergency department visits in the year before the index admission).

The Charlson Comorbidity Index ${ }^{14}$ score was calculated using the methodology initially described by Deyo and colleagues, ${ }^{15}$ who used International Classification of Diseases, 9th revision, codes from administrative data, which was subsequently adapted for use with administrative data using International Classification of Diseases, 10th revision, codes by Quan and colleagues, ${ }^{16}$ Sundararajan and colleagues ${ }^{17}$ and ICES 
(Refik Saskin, ICES, Toronto, Ont.: personal communication, 2017). Information on comorbidities was based on information in the Discharge Abstract Database in the 2 years before the index admission date and on the adjusted diagnostic groups according to information in the Discharge Abstract Database, National Ambulatory Care Reporting System and Ontario Health Insurance Plan databases.

\section{Outcome measures}

Discharge disposition from the index admission as recorded in the Discharge Abstract Database and the date of death from the Registered Persons Database were used to identify inhospital deaths. The Registered Persons Database was also used to determine date of death for those who were discharged alive from the index admission. Hospital admission and discharge dates, obtained from the Discharge Abstract Database, were recorded for all hospital admissions following live index discharge (used to calculate days to all-cause readmission).

\section{Statistical analysis}

All statistical analyses were conducted using SAS software, version 9.5 (SAS Institute). For all statistical tests, an $\alpha$ error of $p \leq 0.05$ was considered significant for 2-sided hypotheses. Standardized differences with a threshold of $0.10^{18}$ were used to compare the distributions associated with baseline covariates between patients with and patients without a family physician. Multivariable logistic regression was used to examine the adjusted association between family physician status and in-hospital mortality. Although data that measure follow-up time (in this case, from index admission discharge to time of death or first readmission in the year following live discharge) can be analyzed using either the Kaplan-Meier method or the Cox proportional hazards model, the latter was selected as this approach allows for the difference between survival times of patients with and without a family physician to be tested while accounting for other factors. ${ }^{19}$ As Cox proportional hazards models do not take into account complex situations where people may be at risk for more than 1 cause of failure ${ }^{20}$ (in this case both readmission to hospital and death), a competing risk proportional hazards model was generated to identify factors associated with 1-year readmission to hospital after live discharge. For all regression models, diagnostics were generated to ensure model assumptions were met.

\section{Ethics approval}

The study was approved by the Thunder Bay Regional Health Sciences Centre Research Ethics Board and the Lakehead University Research Ethics Board.

\section{Results}

Among the 12033 seniors admitted to a medical service at Thunder Bay Regional Health Sciences Centre during the study period, $4899(40.7 \%)$ lacked a family physician, 5666 (47.1\%) were men $(50.2 \%$ of patients without a family physician and $45.0 \%$ of those with a family physician were men; standardized difference 0.11 ), and 2019 (16.8\%) lived in rural areas $(21.7 \%$ of patients without a family physician and $13.4 \%$ of those with a family physician lived in rural areas; standardized difference 0.22 ), suggesting possible access challenges (Table 1).

\section{In-hospital mortality}

A total of 746 people (6.2\%) died during the index admission (8.0\% of people without a family physician and $5.0 \%$ of those with a family physician; standardized difference 0.12 ). In models of in-hospital mortality adjusted for age, sex, income, rurality, past medical history and index admission experience, the odds ratio associated with not having a family physician was 1.56 (95\% confidence interval [CI 1.33-1.83) (Table 2). Sex, age, rurality, admission to the intensive care unit and increasing comorbidity were also associated with significantly increased odds of in-hospital mortality. Model diagnostics supported the regression model (likelihood ratio test $\chi^{2}$ : 935.523, 18 degrees of freedom [df], $p<0.001$; Wald $\chi^{2}$ : 816.57, $18 \mathrm{df}, p<0.001$; C-statistic: 0.814; Hosmer and Lemeshow goodness-of-fit $\chi^{2}: 25.138,8$ df, $\left.p<0.0015\right)$.

\section{Mortality and readmission 1 year after discharge}

Analyses of mortality and readmission 1 year after discharge were conditional on having survived the index hospital admission. Among the 11287 seniors who were discharged alive, $1613(14.3 \%)$ died in the year following discharge from the index admission $(15.8 \%$ of patients without a family physician and $13.3 \%$ of those with a family physician; standardized difference 0.07$)$. The hazard ratio associated with not having a family physician was 1.14 (95\% CI 1.04-1.26) in adjusted models of 1-year postdischarge mortality (Table 2). Although model diagnostics indicated that the model fit the study data (likelihood ratio test $\chi^{2}: 1060.631,18 \mathrm{df}, p<0.001$; Wald $\chi^{2}$ : $1060.608,18 \mathrm{df}, p<0.001)$ and that the proportional hazards assumption was supported, and there was no evidence of collinearity, the C-statistic was only 0.595 , suggesting a relatively poor model.

Almost 5000 people (44.1\%) were readmitted at least once in the year following the index discharge $(48.0 \%$ of patients without a family physician and $41.5 \%$ of those with a family physician; standardized difference 0.13 ). The adjusted subdistribution hazard ratio associated with readmission to hospital for those with no family physician was 1.17 (95\% CI 1.101.24). Further, patients with elective admissions were more likely to be readmitted than those with urgent admissions. Model diagnostics indicate that the proportional hazards assumption was supported (no interaction between time and family physician status).

\section{Interpretation}

Just over $40 \%$ of seniors in the North West Local Health Integration Network who were admitted to the sole regional tertiary care centre did not have a family physician. Although data on the proportion of older adults living without a family physician who require tertiary care is lacking for other Ontario centres, the proportion we observed is certainly high. 


\begin{tabular}{|c|c|c|c|c|}
\hline Characteristic & $\begin{array}{c}\text { Without family } \\
\text { physician } \\
n=4899(40.7 \% \\
\text { of total population) }\end{array}$ & $\begin{array}{c}\text { With family } \\
\text { physician } \\
n=7134(59.3 \% \\
\text { of total population) }\end{array}$ & $\begin{array}{l}\text { Standardized } \\
\text { difference }\end{array}$ & $\begin{array}{c}\text { Total population } \\
n=12033\end{array}$ \\
\hline \multicolumn{5}{|l|}{ Demographic factors } \\
\hline \multicolumn{5}{|l|}{ Age, yr } \\
\hline Mean (SD) & $76.96(7.62)$ & $77.25(7.63)$ & 0.04 & $77.1(7.6)$ \\
\hline Median (IQR) & $77(71-82)$ & $77(71-83)$ & 0.04 & $77(71-83)$ \\
\hline Sex: male, no. (\%) & 2459 (50.2) & $3207(45.0)$ & 0.11 & $5666(47.1)$ \\
\hline Rural, no. (\%) & $1061(21.7)$ & $958(13.4)$ & 0.22 & $2019(16.8)$ \\
\hline \multicolumn{5}{|l|}{ Income quintile, no. (\%) } \\
\hline 1 (lowest) & $1334(27.2)$ & $1653(23.2)$ & 0.09 & $2987(24.8)$ \\
\hline 2 & 925 (18.9) & $1388(19.5)$ & 0.01 & $2313(19.2)$ \\
\hline 3 & $1037(21.2)$ & $1601(22.4)$ & 0.03 & $2638(21.9)$ \\
\hline 4 & $855(17.5)$ & $1425(20.0)$ & 0.06 & $2280(18.9)$ \\
\hline 5 (highest) & $700(14.3)$ & $1032(14.5)$ & 0.01 & $1732(14.4)$ \\
\hline Missing & $48(1.0)$ & $35(0.5)$ & 0.06 & $83(0.7)$ \\
\hline $\begin{array}{l}\text { Patient LHIN: North } \\
\text { West LHIN, no. (\%) }\end{array}$ & 4785 (97.7) & $6992(98.0)$ & 0.02 & 11777 (97.9) \\
\hline \multicolumn{5}{|l|}{ Past medical history } \\
\hline \multicolumn{5}{|c|}{ Charlson Comorbidity Index score, no. (\%) } \\
\hline 0 & $1641(33.5)$ & $2739(38.4)$ & 0.10 & $4380(36.4)$ \\
\hline 1 & $1349(27.5)$ & $1874(26.3)$ & 0.03 & $3223(26.8)$ \\
\hline 2 & $771(15.7)$ & $1106(15.5)$ & 0.01 & $1877(15.6)$ \\
\hline$\geq 3$ & $1138(23.2)$ & $1415(19.8)$ & 0.08 & $2553(21.2)$ \\
\hline \multicolumn{5}{|c|}{ Emergency department visits in the year before index admission } \\
\hline Mean (SD) & $1.73(3.15)$ & $1.42(2.72)$ & 0.11 & $1.55(2.91)$ \\
\hline Median (IQR) & $1(0.2)$ & $1(0-2)$ & 0.10 & $1(0-2)$ \\
\hline \multicolumn{5}{|c|}{ All physician visits in the year before index admission } \\
\hline Mean (SD) & $20.37(21.55)$ & $19.67(16.30)$ & 0.04 & $19.96(18.62)$ \\
\hline Median (IQR) & $16(6-27)$ & $16(9-25)$ & 0.11 & $15(8-26)$ \\
\hline \multicolumn{5}{|l|}{ During index admission } \\
\hline \multicolumn{5}{|c|}{ Admission category of index admission, no. (\%) } \\
\hline Elective & $96(2.0)$ & $147(2.1)$ & 0.01 & $243(2.0)$ \\
\hline Urgent & $3664(74.8)$ & $5696(78.4)$ & 0.09 & $9260(77.0)$ \\
\hline Transfer & $1139(23.2)$ & $1391(19.5)$ & 0.09 & $2530(21.0)$ \\
\hline \multicolumn{5}{|c|}{ Length of stay of index admission, $d$} \\
\hline Mean (SD) & $10.7(18.0)$ & $9.89(17.3)$ & 0.05 & $10.2(17.6)$ \\
\hline Median (IQR) & $6(3-12)$ & $6(3-11)$ & 0.10 & $6(3-12)$ \\
\hline $\begin{array}{l}\text { ICU stay during index } \\
\text { admission, no. (\%) }\end{array}$ & $559(11.4)$ & $758(10.6)$ & 0.03 & $1317(10.9)$ \\
\hline \multicolumn{5}{|l|}{ Outcomes } \\
\hline $\begin{array}{l}\text { In-hospital mortality, } \\
\text { no. (\%) }\end{array}$ & $390(8.0)$ & $356(5.0 \%)$ & 0.12 & $746(6.2)$ \\
\hline $\begin{array}{l}\text { Mortality, } 1 \text { yr after } \\
\text { discharge, no. (\%) }\end{array}$ & $714 / 4509(15.8)$ & $899 / 6778(13.3)$ & 0.07 & $1613 / 11287(14.3)$ \\
\hline $\begin{array}{l}\text { Readmission, } 1 \text { yr after } \\
\text { discharge, no. (\%) }\end{array}$ & $2164 / 4509$ (48.0) & $2816 / 6778$ (41.5) & 0.13 & $4980 / 11287(44.1)$ \\
\hline
\end{tabular}


Table 2: Multivariable regression models of in-hospital mortality, 1-year mortality and 1-year readmission to acute care

\begin{tabular}{|c|c|c|c|}
\hline Variable & $\begin{array}{l}\text { In-hospital mortality } \\
\quad n=12033 \\
\text { OR }(95 \% \mathrm{Cl})\end{array}$ & $\begin{array}{l}\text { Mortality } 1 \text { year } \\
\text { after discharge* } \\
\quad n=11287 \\
\mathrm{HR}(95 \% \mathrm{Cl})\end{array}$ & $\begin{array}{l}\text { Readmission } 1 \text { year } \\
\text { after discharge† } \\
\quad n=11287 \\
\text { SHR }(95 \% \mathrm{Cl})\end{array}$ \\
\hline Without v. with family physician (ref) & $1.56(1.33-1.83)$ & $1.14(1.04-1.26)$ & $1.17(1.10-1.24)$ \\
\hline Age (yr) & $1.04(1.03-1.05)$ & $1.04(1.04-1.05)$ & $1.02(1.01-1.02)$ \\
\hline Sex: male v. female (ref) & $1.31(1.11-1.54)$ & $1.14(1.03-1.26)$ & $1.07(1.01-1.14)$ \\
\hline Income quintile: 2 v. 1 (ref: lowest) & $1.05(0.82-1.34)$ & $1.02(0.89-1.18)$ & $0.94(0.87-1.03)$ \\
\hline Income quintile: 3 v. 1 & $1.14(0.90-1.44)$ & $1.02(0.88-1.17)$ & $0.95(0.87-1.03)$ \\
\hline Income quintile: 4 v. 1 & $1.11(0.87-1.43)$ & $0.97(0.83-1.1)$ & $0.95(0.87-1.03)$ \\
\hline Income quintile: 5 (highest) v. 1 & $1.09(0.84-1.42)$ & $0.89(0.75-1.05)$ & $0.88(0.80-0.97)$ \\
\hline Income quintile: missing v. 1 & $0.75(0.32-1.77)$ & $1.05(0.60-1.85)$ & $0.86(0.61-1.21)$ \\
\hline Charlson score: 1 v. 0 (ref) & $2.50(1.89-3.32)$ & $1.59(1.35-1.87)$ & $1.19(1.10-1.28)$ \\
\hline Charlson score: 2 v. 0 & $3.06(2.27-4.14)$ & $2.83(2.40-3.34)$ & $1.55(1.43-1.69)$ \\
\hline Charlson score: $\geq 3$ v. 0 & $7.06(5.41-9.22)$ & $5.46(4.72-6.31)$ & $1.94(1.79-2.10)$ \\
\hline $\begin{array}{l}\text { No. of physician visits in the year before } \\
\text { the index admission }\end{array}$ & $0.998(0.994-1.002)$ & $1.003(1.001-1.005)$ & $1.008(1.007-1.009)$ \\
\hline $\begin{array}{l}\text { No. of ED visits in the year before the } \\
\text { index admission }\end{array}$ & $1.01(0.99-1.03)$ & $0.99(0.97-1.01)$ & $1.010(1.002-1.018)$ \\
\hline Length of stay of index admission & $1.002(1.000-1.005)$ & $1.004(1.002-1.005)$ & $0.998(0.997-1.000)$ \\
\hline $\begin{array}{l}\text { Admission category of index admission: } \\
\text { elective v. urgent (ref) }\end{array}$ & $0.28(0.09-0.92)$ & $0.90(0.59-1.39)$ & 3.29 (2.69-4.02) \\
\hline $\begin{array}{l}\text { Admission category of index admission: } \\
\text { transfer v. urgent }\end{array}$ & $1.14(0.94-1.39)$ & $1.34(1.19-1.51)$ & $1.12(1.04-1.21)$ \\
\hline ICU: yes v. no (ref) & $5.62(4.73-6.68)$ & $0.80(0.67-0.95)$ & $0.83(0.75-0.92)$ \\
\hline Rural: yes v. no (ref) & $1.41(1.14-1.76)$ & $0.91(0.78-1.05)$ & $1.17(1.08-1.28)$ \\
\hline \multicolumn{4}{|c|}{$\begin{array}{l}\text { Note: } \mathrm{Cl}=\text { confidence interval, } \mathrm{ED}=\text { emergency department, } \mathrm{HR}=\text { hazard ratio, } \mathrm{ICU}=\text { intensive care unit, } \mathrm{OR}=\text { odds ratio, ref = } \\
\text { reference category, } \mathrm{SHR}=\text { subdistribution hazard ratio. } \\
\text { "Cox proportional hazards regression model is conditional on having survived the index hospital admission. } \\
\text { †Subdistribution hazard ratios are from a competing risk proportional hazards regression model. }\end{array}$} \\
\hline
\end{tabular}

We found that $6.2 \%$ of seniors admitted to Thunder Bay Regional Health Sciences Centre for medical reasons died during the index admission, which is similar to the findings of other studies $\left(8.4 \%^{21}\right.$ and $\left.6.2 \%{ }^{22}\right)$. As well, both the proportion of seniors readmitted within 12 months after live index discharge and the proportion who died after discharge were similar to proportions reported in other studies $(44.1 \%$ v. $40.7 \%{ }^{23}$ and $14.3 \%$ v. $12.9 \%,{ }^{24}$ respectively). Among elders without a family physician, the odds of in-hospital mortality increased by $56 \%$. Regression models of 1 -year mortality and readmission also suggested that lack of a family physician was associated with detrimental health outcomes (hazard ratio $1.14,95 \%$ CI 1.04-1.26, and subdistribution hazard ratio $1.17,95 \%$ CI 1.10-1.24, respectively).

While some studies have established the importance of continuity of primary care for health ${ }^{25,26}$ and others have identified characteristics associated with people without a family physician, ${ }^{27,28}$ evidence quantifying the association between family physician status and in-hospital mortality among Canadian seniors is lacking. Further, we were only able to locate
2 studies that examined the association between family physician status and health status after discharge from acute care. In 2002, van Walraven and colleagues ${ }^{29}$ found that among patients (mean age $65.7 \mathrm{yr}$ ) who were admitted to another Ontario tertiary care hospital for an acute medical illness, those who had a family physician had a higher 3-month readmission risk than those who did not. However, in 2010, van Walraven and colleagues ${ }^{30}$ found no association between physician status and 30-day mortality or unplanned readmission among adults (mean age $61.3 \mathrm{yr}$ ) admitted to either a medical or a surgical service at 11 different Ontario hospitals. Although study inclusion criteria, covariates and time to outcome differed by study, the association between family physician status and outcomes after live discharge may be relatively small and mediated or modified by a number of factors.

While other investigators have also noted that people with chronic health conditions but no family physician have higher health care utilization, ${ }^{31}$ in this study the odds ratio, hazard ratio and subdistribution hazard ratio increased with the number of comorbidities; however, the dose-response relationship 
was less pronounced in the 1-year readmission model. Although comorbidity has been identified as a significant predictor of in-hospital mortality ${ }^{21}$ and 1-year mortality, ${ }^{32}$ the findings have been inconsistent. ${ }^{22}$ Some of this inconsistency may be due to how scores are determined. While most investigators have used an additive approach to the calculation of Charlson Comorbidity Index scores and subsequently used categorized or continuous scores, Mehta and coworkers suggest that a multiplicative approach be used for score calculation. ${ }^{33}$ Thus, the reported odds ratio, hazard ratio and subdistribution hazard ratio values associated with comorbidity scores need to be interpreted with caution.

Conceptually, while urgent compared with elective admission status could be considered a marker of admission acuity, it was unknown if patients transferred to Thunder Bay were more similar to those whose admissions were classified as urgent or those whose admissions were classified as elective. In all 3 models, patients who were transferred to tertiary care experienced worse health outcomes than those whose admissions were classified as urgent. The reasons underpinning this finding should be investigated in future studies.

\section{Limitations}

This study has several limitations. First, findings were only adjusted for some factors known to affect mortality and recidivism following a medical admission. For example, although body mass index has been linked to in-hospital ${ }^{34,35}$ and postdischarge mortality, ${ }^{24}$ this factor was not included as a study covariate because height was not captured in any of the databases used to create the inception cohort. Further, as currently there are no culturally relevant, consistent and inclusive Indigenous identifiers in the population data sets that were used for this study, ${ }^{36}$ study findings were not adjusted for ethnocultural identity, a factor known to be associated with the prevalence of several chronic health issues (e.g., diabetes ${ }^{37}$ ) as well as access to urgent medical care. ${ }^{38,39}$ This omission may have led to increased risk estimates associated with family physician status. Future studies could also include other factors such as a measure of why physicians might limit the number of elderly patients in their practices (e.g., medical complexity ${ }^{40}$ ), in addition to self-identified ethnocultural identity and height.

Although rurality and income status were included in the regression models, possible direct, indirect or multiplicative impacts of other social determinants of health (e.g., food and housing) on the study outcomes were not measured. Furthermore, the rural/urban dichotomy used in this study may have been too simplistic. Future studies could determine if Rurality Index of Ontario ${ }^{41}$ scores have a direct effect on the study outcomes or interact with family physician status. Finally, the unique characteristics of the North West Local Health Integration Network may limit the generalizability of the study's findings to other regions in Ontario and Canada. That said, the current study demonstrates the urgency for similar investigations in other jurisdictions, as national policies have recognized the importance of equitable and accessible care for older adults. ${ }^{42}$

\section{Conclusion}

We found that $40.7 \%$ of older adults admitted for medical reasons to Thunder Bay Regional Health Sciences Centre did not have a family physician. Those without a family physician experienced poorer health outcomes both during admission and in the subsequent year. Study findings support the need for further interventions designed to increase seniors' access to family physicians both before hospital admission and after discharge.

\section{References}

1. Piérard E. The effect of physician supply on health status: Canadian evidence. Health Policy 2014;118:56-65.

2. Hay C, Pacey M, Bains N, et al. Understanding the unattached population in Ontario: evidence from the Primary Care Access Survey (PCAS). Healthc Policy 2010;6:33-47.

3. Ionescu-Ittu R, McCusker J, Ciampi A, et al. Continuity of primary care and emergency department utilization among elderly people. CMAJ 2007;177:1362-8.

4. Health Quality Ontario. Health in the north: a report on geography and the bealth of people in Ontario's two northern regions. Toronto: Queen's Printer for Ontario; 2017. Available: http://healthinthenorth.hqontario.ca/ (accessed 2017 Nov. 8).

5. Health Care Connect. Toronto: Ministry of Health and Long-Term Care; 2009 ; modified 2018 May 18. Available: https://hcc3.hcc.moh.gov.on.ca/HCCWeb/ faces/layoutHCCHomePage.jsp?sW=1280\&sH=720\&btype=Firefox\&bver=64 \&ajax $=y$ (accessed 2017 Nov. 22)

6. Health Care Connect: program results. Toronto: Ministry of Health and LongTerm Care; 2008; modified 2018 Dec. 28. Available: www.health.gov.on.ca/en/ $\mathrm{ms} /$ healthcareconnect/public/results.aspx (accessed 2017 Nov. 22).

7. Health fact sheets: chronic conditions, 2016. Cat no 82-625-X. Ottawa: Statistics Canada; 2017 Sept. 27. Available: https://www150.statcan.gc.ca/n1/ pub/82-625-x/2017001/article/54858-eng.htm (accessed 2018 June 6).

8. Merani S, Payne J, Padwal RS, et al. Predictors of in-hospital mortality and complications in very elderly patients undergoing emergency surgery. World 7 Emerg Surg 2014;9:43.

9. Olfson M, Mechanic D, Boyer CA, et al. Assessing clinical predictions of early rehospitalization in schizophrenia. 7 Nerv Ment Dis 1999;187:721-9.

10. Working with ICES data. Toronto: Institute for Clinical Evaluative Sciences. Available: www.ices.on.ca/Data-and-Privacy/ICES-data/Working-with-ICES -Data (accessed 2018 Mar. 23).

11. Data dictionary: library. Toronto: Institute for Clinical Evaluative Sciences. Available: https://datadictionary.ices.on.ca/Applications/DataDictionary/ Default.aspx (accessed 2018 Mar. 23).

12. Postal Code ${ }^{O M}$ Conversion File (PCCF), reference guide. Cat no 92-154-G. Ottawa: Statistics Canada; 2017. Available: www.canadapost.ca/cpc/assets/cpc/uploads/ files/marketing/2017-postal-code-conversion-file-reference-guide-en.pdf (accessed 2018 June 10)

13. Weekend admissions and in-hospital mortality [report]. Ottawa: Canadian Institute for Health Information; 2014. Available: https://secure.cihi.ca/free_products/ Mortality_Report_2014_en.pdf (accessed 2017 Mar. 10).

14. Charlson ME, Pompei P, Ales KL, et al. A new method of classifying prognostic comorbidity in longitudinal studies: development and validation. 7 Chronic Dis 1987;40:373-83.

15. Deyo RA, Cherkin DC, Ciol MA. Adapting a clinical comorbidity index for use with ICD-9-CM administrative databases. 7 Clin Epidemiol 1992;45:613-9.

16. Quan H, Sundararajan V, Halfon P, et al. Coding algorithms for defining comorbidities in ICD-9-CM and ICD-10 administrative data. Med Care 2005;43:1130-9.

17. Sundararajan V, Henderson T, Perry C, et al. New ICD-10 version of the Charlson comorbidity index predicted in-hospital mortality. 7 Clin Epidemiol 2004;57:1288-94.

18. Austin PC. An introduction to propensity score methods for reducing the effects of confounding in observational studies. Multivariate Behav Res 2011;46:399-424.

19. Bewick V, Cheek L, Ball J. Statistics review 12: survival analysis. Crit Care 2004;8:389-94.

20. Fine JP, Grey RJ. A proportional hazards model for the subdistribution of a competing risk. 7 Am Stat Assoc 1999;94:496-509.

21. Ayaz T, Sahin SB, Sahin OZ, et al. Factors affecting mortality in elderly patients hospitalized for non-malignant reasons. 7 Aging Res 2014;2014: 584315 .

22. Tal S, Guller V, Shavit Y, et al. Mortality predictors in hospitalized elderly patients. Q7M 2011;104:933-8.

23. Morrissey EFR, McElnay JC, Scott M, et al. Influence of drugs, demographics and medical history on hospital readmission of elderly patients. Clin Drug Investig 2003;23:119-28. 
24. Liu L, Bopp MM, Roberson PK, et al. Undernutrition and risk of mortality in elderly patients within 1 year of hospital discharge. 7 Gerontol A Biol Sci Med Sci 2002;57:M741-6.

25. Menec VH, Sirski M, Attawar D, et al. Does continuity of care with a family physician reduce hospitalizations among older adults? 7 Health Serv Res Policy 2006;11:196-201.

26. Bayliss EA, Ellis JL, Shoup JA, et al. Effect of continuity of care on hospital utilization for seniors with multiple medical conditions in an integrated health care system. Ann Fam Med 2015;13:123-9.

27. Reid GJ, Freeman TR, Thind A, et al. Access to family physicians in southwestern Ontario. Healthc Policy 2009;5:e187-206.

28. Talbot Y, Fuller-Thomson E, Tudiver F, et al. Canadians without regular medical doctors: Who are they? Can Fam Physician 2001;47:58-64.

29. van Walraven C, Seth R, Austin PC, et al. Effect of discharge summary availability during post-discharge visits on hospital readmission. 7 Gen Intern Med 2002;17:186-92.

30. van Walraven C, Dhalla IA, Bell C, et al. Derivation and validation of an index to predict early death or unplanned readmission after discharge from hospital to the community. CMA7 2010;182:551-7.

31. Glazier RH, Moineddin R, Agha MM, et al. The impact of not having a primary care physician among people with chronic conditions: ICES investigative report. Toronto: Institute for Clinical Evaluative Sciences; 2008. Available: www.ices. on.ca/Publications/Atlases-and-Reports/2008/The-impact-of-not-having (accessed 2017 Nov. 24)

32. Gené Badia J, Borràs Santos A, Contel Segura JC, et al.; HC>65 Research Team. Predictors of mortality among elderly dependent home care patients. BMC Health Serv Res 2013;13:316.

33. Mehta HB, Mehta V, Girman C, et al. Regression coefficient based scoring system should be used to assign weights to the risk index. 7 Clin Epidemiol 2016;79:22-8.

34. Yamauchi $\mathrm{Y}$, Hasegawa $\mathrm{W}$, Yasunaga $\mathrm{H}$, et al. Paradoxical association between body mass index and in-hospital mortality in elderly patients with chronic obstructive pulmonary disease in Japan. Int 7 Chron Obstruct Pulmon Dis 2014;9:1337-46.

35. Potter JF, Schafer DF, Bohi RL. In-hospital mortality as a function of body mass index: an age-dependent variable. 7 Gerontol 1988;43:M59-63.

36. Smylie J, Firestone $M$. Back to the basics: identifying and addressing underlying challenges in achieving high quality and relevant health statistics for indigenous populations in Canada. Stat 7 IAOS 2015;31:67-87.

37. Canadian Diabetes Association Clinical Practice Guidelines Expert Committee; Harris SB, Bhattacharyya O, Dyck R, et al. Type 2 diabetes in Aboriginal peoples. Can 7 Diabetes 2013;37(Suppl 1):S191-6.

38. Marrone S. Understanding barriers to health care: a review of disparities in health care services among indigenous population. Int 7 Circumpolar Health 2007;66:188-98.

39. Newbold KB. Aboriginal physician use in Canada: location, orientation and identity. Health Econ 1997;6:197-207.

40. Adams WL, McIlvain HE, Lacy NL, et al. Primary care for elderly people: Why do doctors find it so hard? Gerontologist 2002;42:835-42.
41. Kralj B. Measuring rurality — RIO2008_BASIC: methodology and results. Toronto: Economics Department, Ontario Medical Association; 2009. Available: www.oma.org/wp-content/uploads/2008rio-fulltechnicalpaper.pdf (accessed 2018 Mar. 23).

42. Sinha SK, Griffin B, Ringer T, et al. An evidence-informed national seniors strategy for Canada. 2nd ed. Toronto: Alliance for a National Seniors Strategy; 2016. Available: http://nationalseniorsstrategy.ca/wp-content/uploads/2016/10/ National-Seniors-Strategy-Second-Edition.pdf (accessed 2017 Nov. 24).

Affiliations: Division of Geriatric Medicine (Peel), Department of Medicine, Schulich School of Medicine \& Dentistry; Lawson Health Research Institute (Gutmanis), London, Ont.; Northern Ontario School of Medicine (Bon); Thunder Bay Regional Health Sciences Centre and St. Joseph's Care Group (Bon), Thunder Bay, Ont.

Contributors: Alexandrea Peel developed the study concept and design and participated in acquiring and interpreting the data and writing the article. Iris Gutmanis assisted with analzying and interpreting the data as well as writing the article. Trevor Bon contributed to the study concept and design, assisted with data interpretation and critically reviewed the manuscript. All of the authors gave approval of the final version for publication and agreed to be accountable for all aspects of the work.

Funding: Financial support for this project was provided by a Clinical Innovation Opportunities Grant from the Northern Ontario Academic Medicine Association.

Disclaimer: This study was supported by ICES, which is funded by an annual grant from the Ontario Ministry of Health and Long-Term Care (MOHLTC). It made use of de-identified data from the ICES Data Repository, which is managed by ICES with support from its funders and partners: Canada's Strategy for Patient-Oriented Research, the Ontario Strategy for Patient-Oriented Research Support Unit, the Canadian Institutes of Health Research and the Government of Ontario. The opinions, results and conclusions reported in this article are those of the authors and are independent of the funding sources. No endorsement by ICES or any of its funders or partners is intended or should be inferred. Parts of this material are based on data and information compiled and provided by the Canadian Institute for Health Information. However, the analyses, conclusions, opinions, and statements expressed herein are those of the authors and not necessarily those of the Canadian Institute for Health Information.

Supplemental information: For reviewer comments and the original submission of this manuscript, please see www.cmajopen.ca/content/7/1/ E94/suppl/DC1. 